\title{
MUSEOLOGIA E ARQUITETURA: UMA CATALISADORA RELAÇÃO À EDUCAÇÃO POR MEIO DA READEQUAÇÃO DO ACERVO EDUCACIONAL DE CIÊNCIAS NATURAIS DA UNOESTE
}

\author{
Carla Zanetti Segatto', Fabrícia Dias da Cunha Borges', Graziella Plaça Orosco de Souza², Antonio Fluminhan \\ $\mathrm{Jr}^{3}$
}

Universidade do Oeste Paulista - UNOESTE, ${ }^{1}$ Curso de Arquitetura e Urbanismo. ${ }^{2}$ Mestrado em Meio Ambiente e Desenvolvimento Regional. ${ }^{3}$ Pró-Reitoria de Pesquisa e Pós-Graduação, Presidente Prudente, SP. E-mail: fluminhan@unoeste.br

\section{RESUMO}

A presente pesquisa analisou meios de intervir qualitativamente no ambiente do Acervo Educacional de Ciências Naturais (AECIN), mantido pela Universidade do Oeste Paulista (UNOESTE), de modo a resultar em uma relação catalisadora para a educação e promover um aumento no interesse da sociedade por suas atividades. Os objetivos envolveram a transformação em um espaço arquitetonicamente confortável e visivelmente agradável. Foi analisado o projeto existente, o que resultou em propostas de readequação do lugar, visando à melhoria da qualidade do ambiente e a sua maximização de uso, atingindo não só a comunidade acadêmica, mas também a sociedade civil. Para tanto, foram elaboradas propostas temáticas para readequação das exposições como estratégias educacionais em relação ao meio ambiente. Além da adequação do espaço físico, foram elaboradas propostas na promoção de visitas virtuais, acompanhando a contemporaneidade dos acervos museológicos. Pode-se concluir que essa pesquisa contribuiu para a transformação da realidade do acervo analisado, promovendo a interdisciplinaridade e a prática da educação ambiental.

Palavras-chave: Readequação arquitetônica, Acervo Educacional, Ciências Naturais, Universidade do Oeste Paulista, Interdisciplinaridade.

\section{MUSEOLOGY AND ARCHITECTURE: A CATALYST RELATION TO EDUCATION THROUGH THE READJUSTMENT OF UNOESTE'S EDUCATIONAL COLLECTIONS OF NATURAL SCIENCES}

\begin{abstract}
This research examined ways to intervene qualitatively in the environment of the Educational Collections of Natural Sciences (AECIN), maintained by the University of Western São Paulo (UNOESTE), in order to result in a catalyst relation to education, and to promote an increase in society interest in their activities. The studies have focused on to transform it into a architecturally comfortable and noticeably pleasant space. It was analyzed the existing project, which resulted in proposals to readjust the place, aiming to improve the quality of the environment and maximizing its use, attending not only the academic community but also civil society. Several thematic proposals have been made to adjust the exhibition as educational strategies in relation to the environment. In addition to the adequacy of the physical space, proposals were elaborated for the promotion of virtual tours, following the contemporaneity of museum collections. We conclude that this research contributed to the transformation of reality of the analyzed collections, promoting the interdisciplinarity and practices of environmental education.

Keywords: Architectural readjustment, Educational Collection, Natural Sciences, University of Western São Paulo, Interdisciplinarity.
\end{abstract}

\section{INTRODUÇÃO}

O museu, em sua totalidade arquitetônica, iniciou-se como antigo museu "depósito", passando pela conceituação de centro multifacetado de cultura e mistura de museus (SUANO, 1986; KIEFER, 2002). Após a organização espacial destes conceitos, deu-se o primeiro passo para a evolução da caixa estática e fechada, acadêmica e simétrica, para uma forma inédita e cinemática (MONTANER, 2003); 
Ou seja, um novo museu ativo e dinâmico. Efeito este que foi provocado diretamente pela arquitetura.

Evoluindo nesta linha de pensamento, a arquitetura dos museus se transformou em uma gigantesca escultura, e é vista com um boom de crescimento. Esses testemunhos passam, então, por fases alternadas por completo abandono quando são esquecidos, escondidos ou simplesmente destruídos. Fases estas seguidas, quase sempre, de períodos de "revalorização". Além de resolver seu programa funcional, a missão primordial da arquitetura é expressar o conteúdo do museu como coleção e também como edifício cultural e público.

Suano (1986) menciona em sua obra que a formação de coleções de objetos é provavelmente quase tão antiga quanto $o$ homem e, contudo, sempre guarda significados diversos, dependendo do contexto em que se insere. Acrescenta-se que, os estudiosos do colecionismo acreditavam que recolher aqui e ali objetos e "coisas" era como recolher pedaços de um mundo que se quer compreender e do qual se quer fazer parte ou dominar. Suano (1986) afirma que: "foram os romanos, aliás, os grandes colecionadores da Antiguidade" (SUANO, 1986, p.12).

A origem da instituição museológica apresenta uma conexão com a cultura e a sociedade, como defende Santos (2000), ao dizer que as formas que o museu tem para se apresentar e as denominações que pode adquirir fazem dessa instituição, se bem administrada, organismo com profunda ação/função social, geradora de nossas experiências e que exerce importante papel com relação à cultura e a sociedade.

Santos (2000) considera ainda o museu de outra perspectiva: como um fórum de debates, pontuando, ainda, que uma das formas de efetivação desse fórum é justamente o estabelecimento de múltiplas relações com a comunidade. Essa linha tênue de relações iniciase em 1840, onde a situação era bastante caótica quanto às exposições. Suano (1986) afirma esse fato ao pontuar que, "materiais diversos eram colocados ao acaso, com parca identificação, amontoados, sem iluminação" (SUANO, 1986, p.30).

Suano (1986) destaca também que os museus mais antigos da América do Sul são os da Escola Nacional de Belas Artes do Rio de Janeiro e o Museu Nacional do Rio de Janeiro (Museu
Real), criados por iniciativa de D. João VI nos moldes europeus. $\mathrm{O}$ mesmo autor descreve que nos EUA se encontram, atualmente, alguns dos maiores museus do mundo. $O$ Museu de Charleston, na Carolina do Sul, é considerado o mais antigo e um dos melhores daquele país. No entanto, o público se sentia pouco à vontade neles, deslocando-se em meio a tanta grandiosidade.

Tendo-se em vista as características dos principais museus e acervos universitários no Brasil, o Acervo Educacional de Ciências Naturais (AECIN), mantido pela Universidade do Oeste Paulista - UNOESTE, e que é o local de intervenção deste estudo, foi organizado para preservar o patrimônio natural em Presidente Prudente - SP e ainda promover o interesse dos visitantes pelas Ciências Naturais, por meio de exposições, educação e pesquisa.

A presente pesquisa procurou promover e dar visibilidade a um local com significativa riqueza de patrimônio, aliando interdisciplinaridade e trazendo uma intervenção arquitetônica neste espaço. Seguindo a evolução da instituição museológica enquanto configuração arquitetônica tem-se que esta pesquisa analisou este espaço e traduziu a fundamentação em propostas de melhorias, baseadas em estudos históricos, uso das normativas museológicas, bem como de estratégias educacionais para melhoria do ambiente.

A proposta resultante é intervir qualitativamente no ambiente do Acervo Educacional de Ciências Naturais da UNOESTE, e promover o aumento no interesse social por seu patrimônio alcançando, não só a comunidade acadêmica, mas também a sociedade civil.

\section{METODOLOGIA}

Esta pesquisa foi realizada através da análise sintática entre teoria e prática, resultando em propostas de readequação de uma coleção museológica. Definindo-se como qualitativa de campo se delimitando, porém, a ser dedutiva.

Para isto foram utilizadas bases de dados digitais, levantamento de referenciais teóricos específicos e foram consultados os órgãos regulamentadores de esfera municipal, estadual, federal e internacional, cujos fundamentos são de sobressalente importância, e cujas homepages oficiais disponibilizam vasto material de domínio público que foram utilizados nesta pesquisa, tais como: o Instituto Brasileiro de Museus (IBRAM) 
(http://www.museus.gov.br/), o Conselho Federal de Museologia (COFEM) (http://cofem.org.br/), Associação Brasileira de Ecomuseus e Museus Comunitários (ABREMC) (http://www.abremc.com.br/), e o Conselho Internacional de Museus através de seu Comitê Brasileiro (http://icom.org.br). No intuito de levantar e analisar as normativas vigentes com relação à atividade em instituições museológicas, fundamentando análise espacial e intervenção resultante proposta.

\section{Local de Intervenção: o Acervo Educacional de Ciências Naturais (AECIN) da UNOESTE}

O Acervo Educacional de Ciências Naturais (AECIN) foi criado em maio de 2008 na Faculdade de Artes, Ciências, Letras e Educação de Presidente Prudente (FACLEPP), da Universidade do Oeste Paulista (UNOESTE), como um espaço interdisciplinar destinado ao desenvolvimento de atividades científicas, educativas, culturais e de extensão à comunidade de Presidente Prudente (SP) e toda a região do Oeste Paulista. Constitui-se de um museu de Ciências Naturais universitário que, segundo Souza (2015, p. 68), possui um total de 5.550 amostras/peças distribuídas em dezoito coleções ${ }^{1}$.

De acordo com o documento que 0 regulamenta (UNIVERSIDADE DO OESTE PAULISTA, 2013), o AECIN constitui-se em espaço de educação que está a serviço da sociedade e do seu desenvolvimento, zelando pela conservação e pela perpetuação da memória ambiental regional e nacional.

Uma descrição mais detalhada das atividades desenvolvidas no âmbito do AECIN é apresentada por Souza (2015, p. 64),

Neste departamento são promovidas atividades extracurriculares, estimulando-se o desenvolvimento de pesquisas em um ambiente adequado, contribuindo deste modo para com a melhoria da qualidade do ensino. Reconhecidamente, as visitas escolares e o

\footnotetext{
${ }^{1}$ As seções/coleções do AECIN segundo estão organizadas em: 1. Anfíbios, 2. Animais dulcícolas, 3. Animais marinhos, 4. Aracnídeos, 5. Artefatos, 6. Aves (incluindo seus ovos), 7. Cobras e serpentes, 8. Fósseis, 9. Fungos (incluindo os cogumelos comestíveis), 10. Herbários e exsicatas, 11. Insetos, 12. Madeiras, 13. Mamíferos (incluindo os fetos perfeitos e com anomalias congênitas), 14. Minerais, 15. Peixes, 16. Répteis diversos, 17. Rochas, 18. Sementes.
}

aproveitamento do espaço oferecido pelo acervo para o desenvolvimento de pesquisa e ações extensivas caracterizam-no como um museu didático. As atividades de monitoria contribuem para o aprofundamento teórico, reflexão e interesse em novas áreas de pesquisa científica.

Ao desenvolver atividades de monitoria em visitas e estágios supervisionados curriculares no departamento, os acadêmicos entram em contato com a realidade educacional, pública e particular, das escolas visitantes, possibilitando a eles reflexão sobre metodologias de ensino de meio ambiente em espaço privilegiado a esta finalidade.

\section{Análise Arquitetônica Espacial do Acervo Educacional de Ciências Naturais}

Atualmente, sabe-se que "cerca de $60 \%$ dos museus e centros de ciências existentes no Brasil pertencem a universidades" (SANTOS, 2006), e que apenas $18 \%$ são privadas. Este fato pode ser facilmente percebido quando se analisam as origens e representações das coleções museológicas, bem como o trabalho educativo realizado no interior dessas instituições. Pode ser considerado um museu universitário aquele que está parcial ou totalmente sob a responsabilidade de uma universidade (gestão, salvaguarda do acervo, recursos humanos e espaço físico).

O Acervo Educacional de Ciências Naturais (AECIN), objeto deste estudo, é mantido pela Universidade do Oeste Paulista (UNOESTE), que está instalada na cidade de Presidente Prudente, região oeste do Estado de São Paulo. A pesquisa analisou espacialmente o departamento, enfatizando que as propostas estão de acordo com as normativas dos órgãos oficiais regulamentadores.

À primeira vista, considera-se que o espaço em questão, tal como utilizado na atualidade, está distante de ser, como definiu Santos (2000), um museu "palácio", pois se desenvolve em um volume único de uma sala de aula, desatento à ser formalmente atrativo, tão quanto seguindo este pensamento, adere às ideias de "museus modernos", definidos como "organismos singulares" de Montaner (2003). 
Tais características colaboram para a defluência de visitantes e a relevância mínima científica, educativa e social; diretriz norteadora do funcionamento de uma coleção museológica mantida por uma Universidade.

No que integra o primeiro espaço do AECIN (expositor) em sua configuração atual, nota-se destacável organização em sua temática, mas molda-se a uma circulação mínima diante de notável exposição. Coleção esta que se restringe à mesma tonalidade, deixando a dinâmica do espaço menos fluida, possuindo uma porta de madeira comum que impede reconhecimento não só pela sociedade civil, mas até mesmo pela própria comunidade acadêmica em questão. Não existindo, também, espaços destinados exclusivamente à recepção, acolhimento e organização e cadastro/identificação dos grupos de visitantes.

Ao que contempla a segunda área (técnica), têm-se um espaço necessário, porém não ideal, ao se delinear um local multifuncional, sobrecarregado, funcionando simultaneamente: sala para procedimentos técnicos, biblioteca depositária, arquivos de documentos, coleções reserva e materiais laboratoriais, entre outros. Não obstante é o local de maior incidência solar, prejudicial a diversas destas atividades.
Pode-se analisar positivamente no que se refere ao estado geral de conservação do edifício e o bom funcionamento das instalações, aspectos fundamentais na determinação da qualidade ambiental proporcionada às coleções e aos usuários. No momento, inexistem espaços destinados a atividades administrativas, espaço de serviços, setor educativo (tanto do ponto de vista acadêmico como também para ações educativas, culturais e de capacitação profissional, tais como palestras e minicursos) e nem mesmo sala para reuniões.

A seguir têm-se o levantamento metodológico feito no espaço atual do acervo, indicando seu fluxo, organização e layout (Figura 1). A partir desta imagem inicial, foi dado o primeiro passo para a evolução da "caixa estática e fechada, acadêmica e simétrica", segundo a caracterização feita aos museus de 1850, por Montaner (2003). Foi estabelecido como meta, para o espaço museológico em questão, atingir uma forma inédita, um novo museu ativo e dinâmico, contemplando a designação dos museus atuais. Foi estabelecido o princípio que a arquitetura constitui a primeira peça fundamental aos museus.
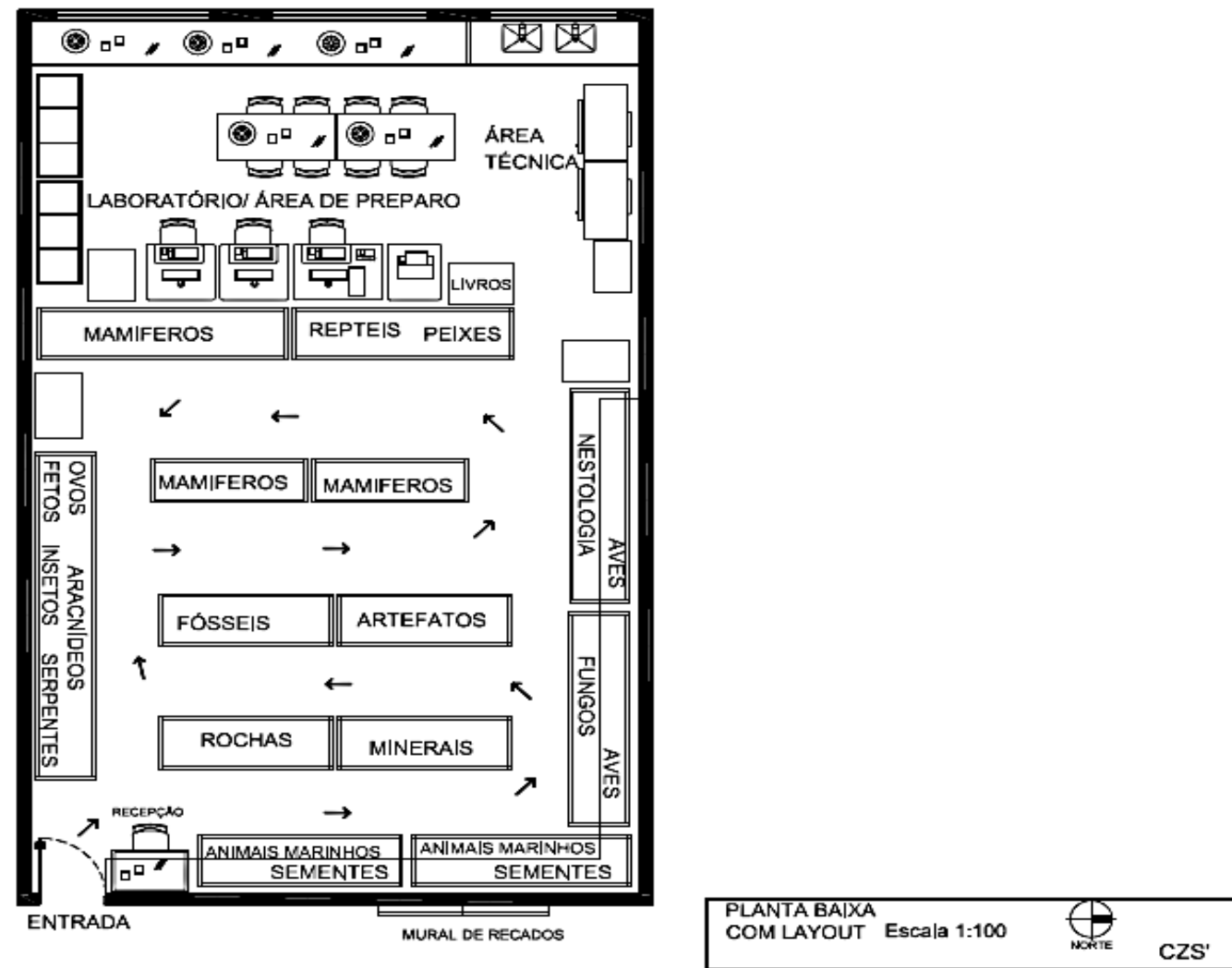

Figura 1. Planta baixa atual com layout do $A E C I N$ e disposição de suas seções.

Fonte: AutoCAD ${ }^{\circledast}$. Editado pelo autor em: 05 jun. 2016. 


\section{RESULTADOS}

Visando a readequação e maximização do ambiente em que se insere o AECIN, foi elaborada uma proposta inicial envolvendo a melhoria na circulação e fluxo, e um estudo de maior permeabilidade visual identificação de percursos e nas condições de acesso, no sentido de ser reconhecido incontestavelmente. Preconiza-se o projeto de um volume formal mais indicado a espaços museológicos atuais traduzindo-o assim formalmente atrativo.

Faz-se substancial proposta indicar à exposição de peças da coleção analisada, algum aporte atrativo complementar tonal. Pretendese, assim, a otimização do acesso aos itens, maximizando-se o uso das informações contidas e, sobretudo, sendo uma proposta destacável e direta como instrumento educacional para todas as idades, criando assim o desenvolvimento conceitual através da ideia de ícones.

É sugerido por inclusão que um destes ícones seja desenvolver projetos em espaços conectados ao museu - ao ar livre, pois o aumento de programas e projetos educativos nos museus faz parte do que se pode chamar segundo documento publicado pelo Instituto Brasileiro de Museus do Ministério da Cultura (IBRAM/MinC), intitulado "Subsídios para a criação de Museus Municipais" (BRASIL, 2009) de "alfabetização visual" ou "alfabetização museal", onde a experiência tridimensional é possível na aplicação da temática deste acervo ao seu contexto, aumentando a relação do usuário ao meio ambiente e fazendo-os resgatar sensibilidade à percepção e ao toque do natural, com aplicação imediata do conhecimento adquirido.

Acompanhando a contemporaneidade das coleções museológicas atuais, a pesquisa manifesta-se a favor do desenvolvimento de maquetes eletrônicas, análise de softwares e estudo do aprimoramento e visibilidade da homepage existente, podendo-se desenvolver uma planta baixa para delinear o trajeto desta visita virtual, monitorada eletronicamente e, inclusive, com imagens reais das peças visto que os museus atualmente são considerados instituições dinâmicas, abertas ao futuro.

Para tanto, inicialmente, indicou-se um percurso em formato de patas, a fim de que os visitantes fossem norteados a descobrirem este espaço antes recôndito em uma sala do subsolo da universidade, como demonstra a indicativa da Figura 2 a seguir.

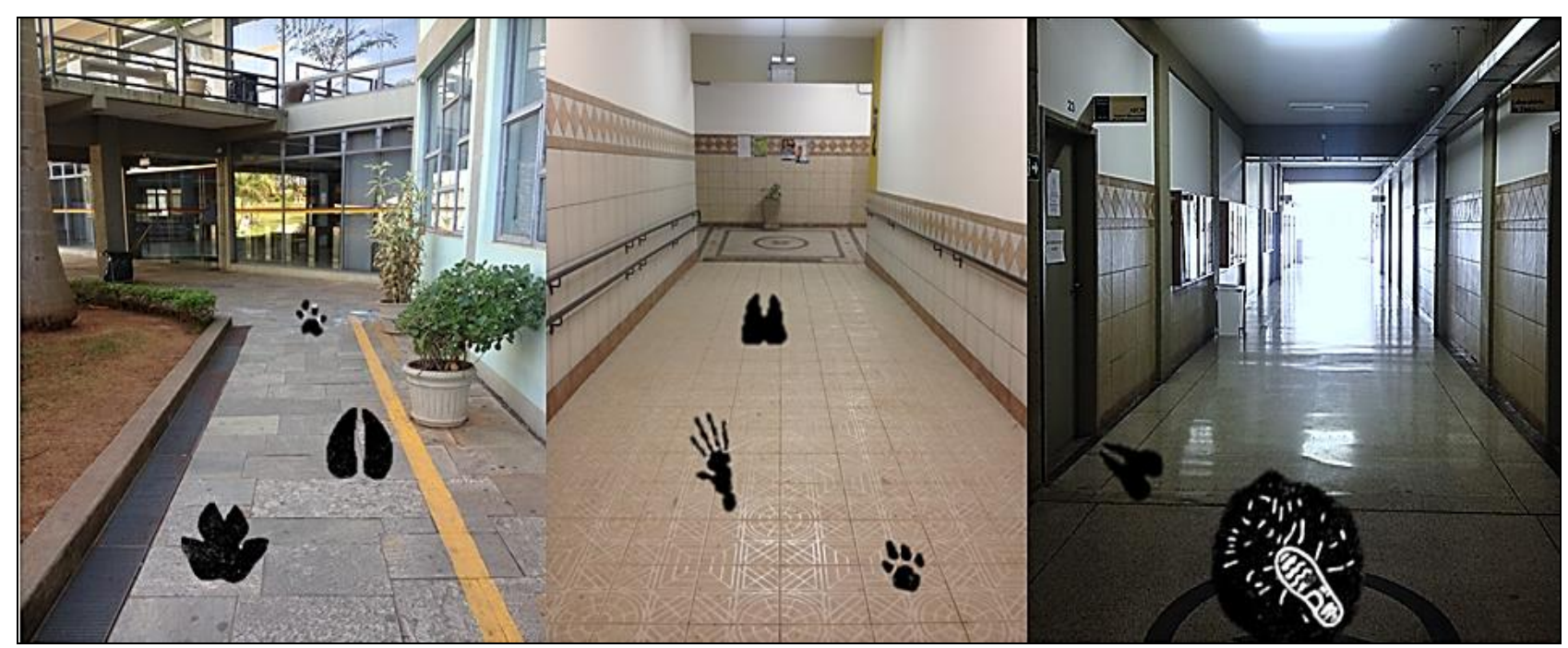

Figura 2. Estudo de intervenção para percurso norteador dos visitantes até a exposição do AECIN. Fonte: Autora (2016). Sem escala.

Em uma segunda etapa, arquitetonicamente sugere-se que seja acrescentada alguma intitulação nominal que indique, de forma mais visível, o acervo em seu espaço destinado, podendo ser feito em forma de placa, para acompanhar o padrão de sua mantenedora UNOESTE e para que seja algo transportável, como indica o estudo da Figura 3. 


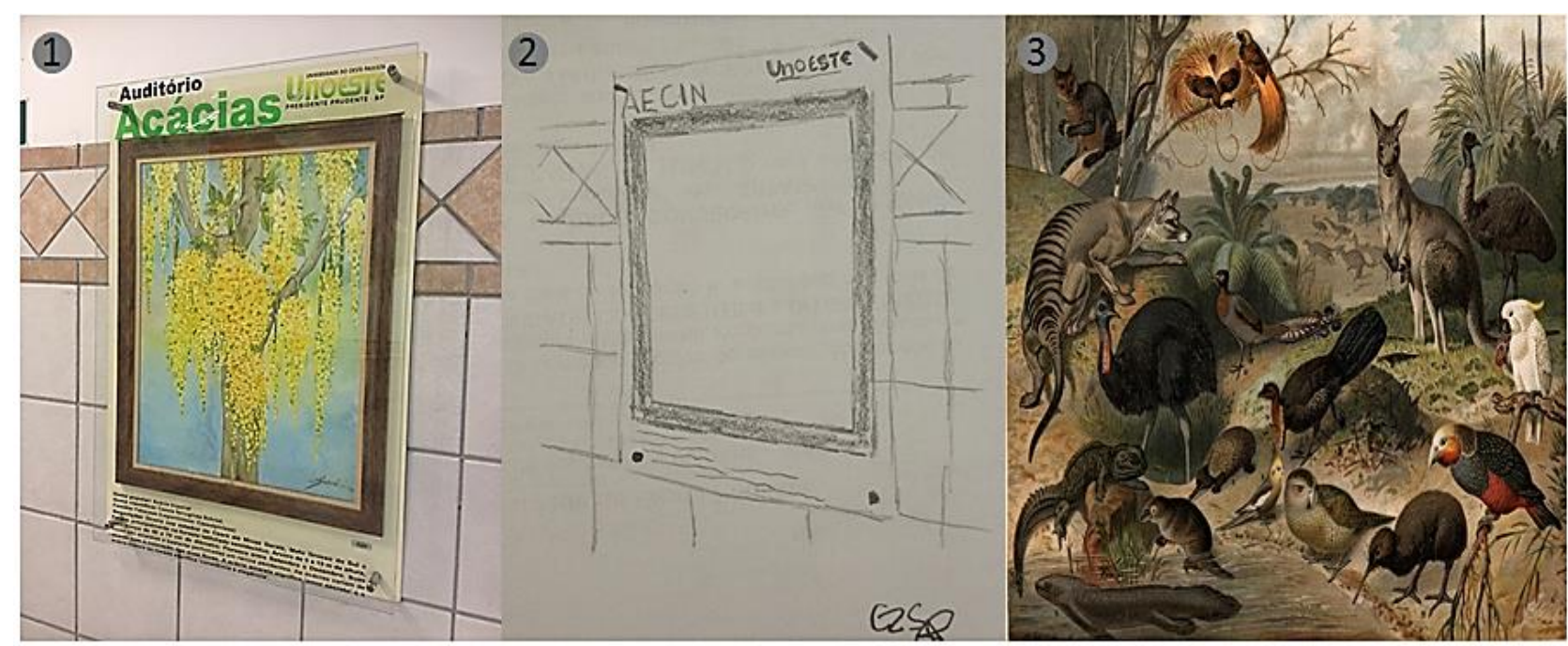

Figura 3. Estudo de placa nominal indicativa para a fachada do AECIN.

Fonte: (1) e (2) Autora (2016). (3) <https://www.etsy.com/au/listing/130452298/1894-antique-lithograph-ofaustralian>. Acesso em: 26 jun. 2016.

$\mathrm{Na}$ entrada, enquanto se tem a readequação da porta, sendo esta atualmente de madeira não permitindo interatividade $e$ permeabilidade visual, sugere-se reaproveitar moldes da original, acrescentando uma janela de vidro em disposição vertical, permitindo a máxima permeabilidade visual, tal como apresentado na Figura 4.

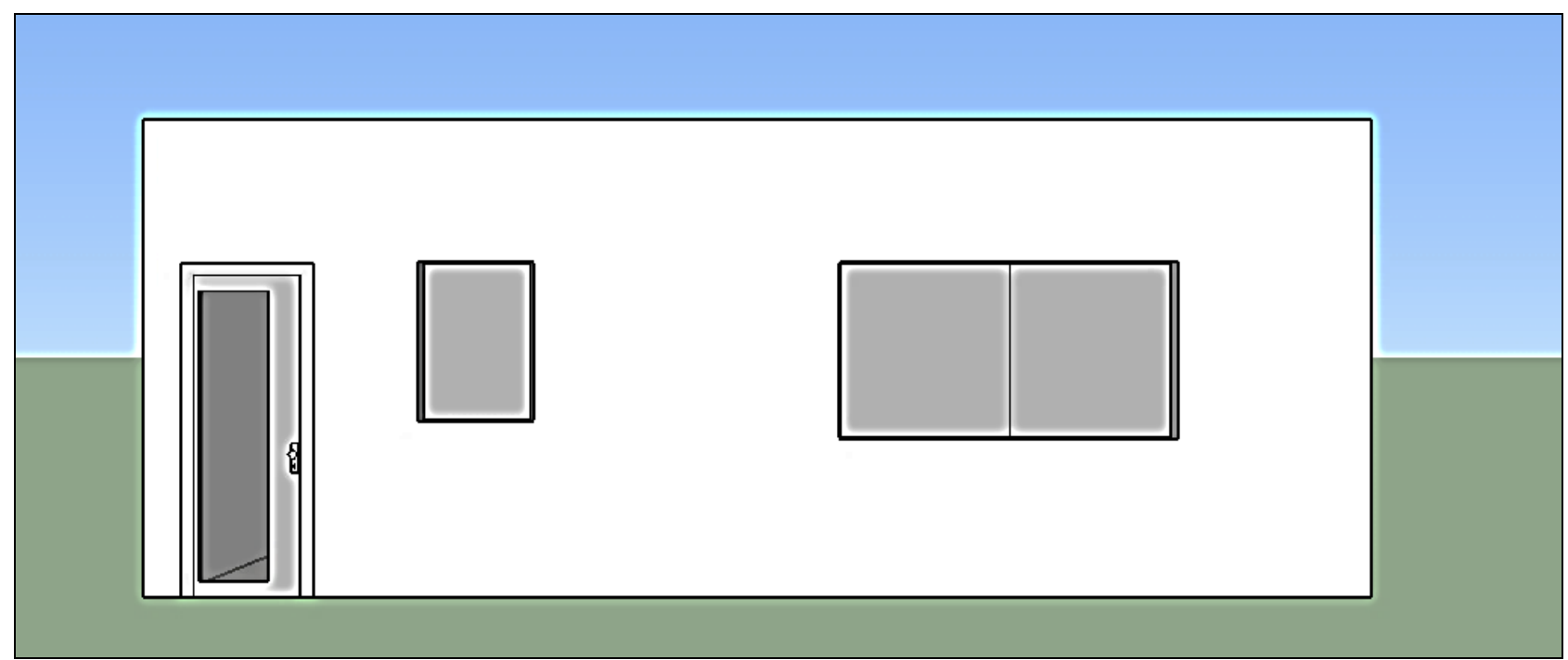

Figura 4. Proposta para a porta de entrada e fachada do Acervo Educacional de Ciências Naturais Fonte: Autora (2016). Sem escala.

Em seu interior, a visibilidade que pretende este trabalho poderá ser alcançada através do estudo de reorganização do acervo, como indica o trabalho de Faubert e Crepon (1990) com a teoria dos cinco elementos de Wu
Xing: fogo, terra, metal, água e madeira/árvore (Figura 5), que são os elementos básicos que formam o mundo material existente, tão quanto à natureza em que este acervo é formado. 


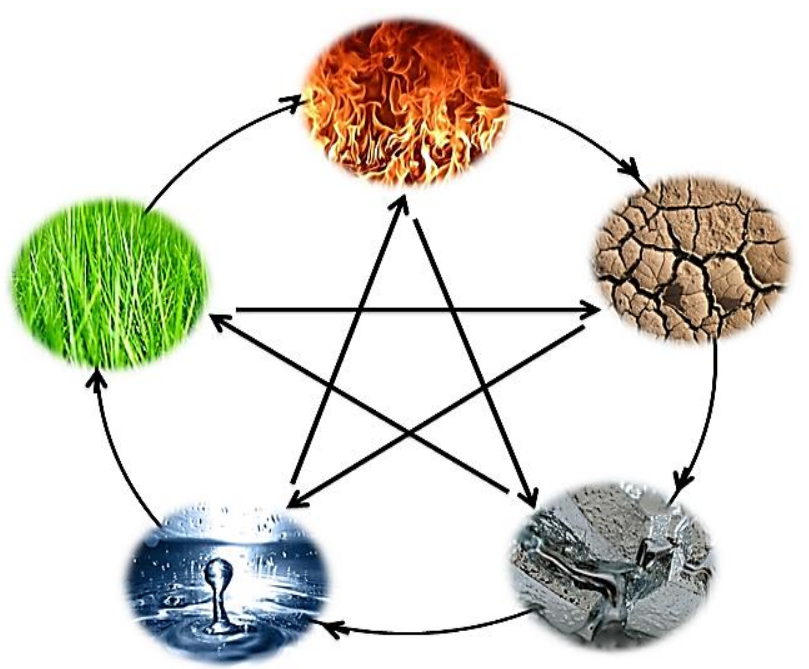

Figura 5. Elementos Wu Xing, conceito norteador para reorganização do Acervo Educacional de Ciências Naturais.

Fonte: <https://bemviverbem.wordpress.com/elementos>. Acesso em: 26 jun 2016.

Este conceito estabelece uma integração de controle reciproco entre estes materiais, tal como o acervo estabelece, e será fortificado ao ser reorganizado com controle de ressaltar e promover constante estado de movimento e mudança, tal como a natureza das Ciências Naturais. Deste modo, a proposta de intervenção inicia-se com o elemento água, onde seria reorganizado em cubos de vidro sobrepostos readequando somente o acervo marinho, como expressa a Figura 6, liberando mais espaço para a outra seção.

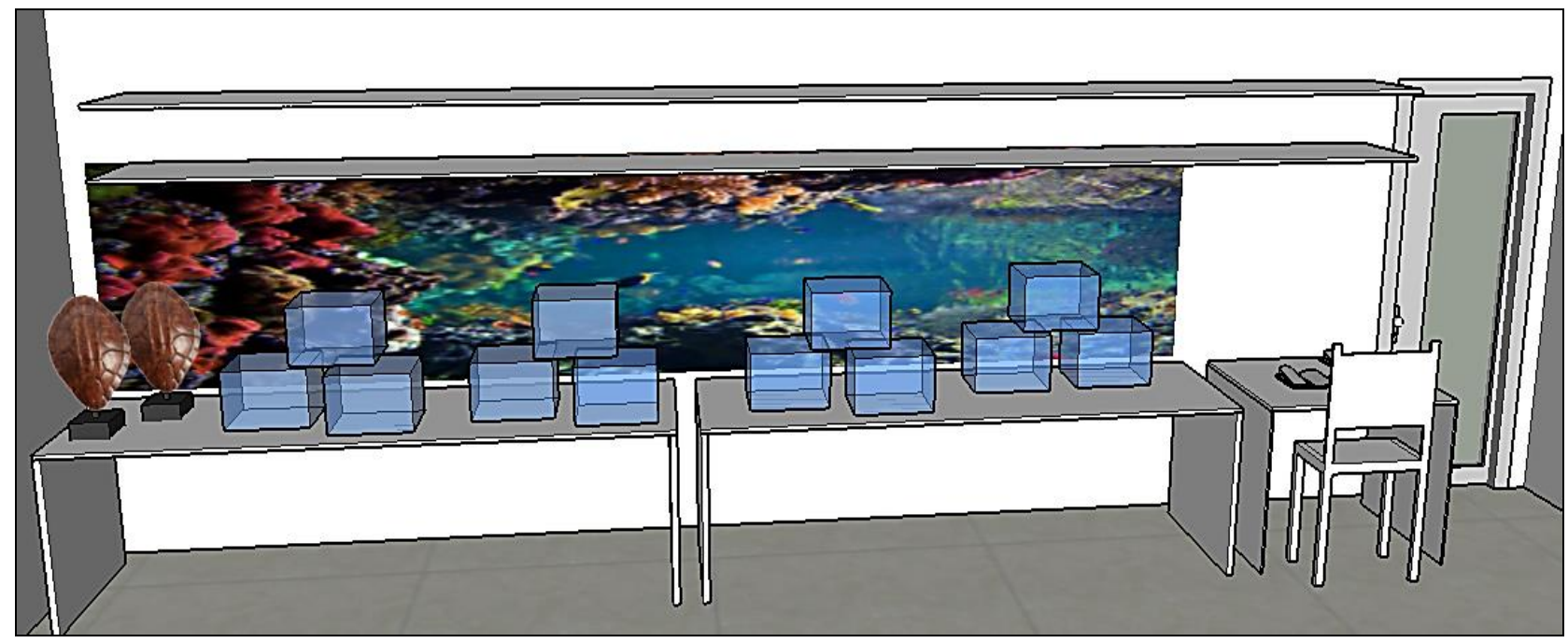

Figura 6. Projeção do elemento água, reorganizando o acervo de animais marinhos.

Fonte: Autora (2016). Sem escala.

Visto que estes cubos uniformizariam a linearidade que o acervo já traz, remete a coletividade e sobreposição com que os animais marinhos se apresentam na natureza. Este painel indicativo tornaria mais educativa à proposta, levando à compreensão dos visitantes, especialmente das crianças, em relação ao conteúdo, além de acobertar a tubulação de energia e o suporte da mão francesa que apoia a prateleira superior atualmente aparente.
Organizando desta maneira em uma parede só, seria liberado espaço para a readequação da seção seguinte. Esta que pela teoria é a do elemento madeira/árvore, onde por estudo poderão se concentrar os seres correlacionados diretamente com este elemento, sendo estes: aves, fungos, inclusive o acréscimo do acervo de sementes e troncos, conforme indica a Figura 7 , complementando a exposição proposta com o bicho preguiça que estava deslocado dos demais. 


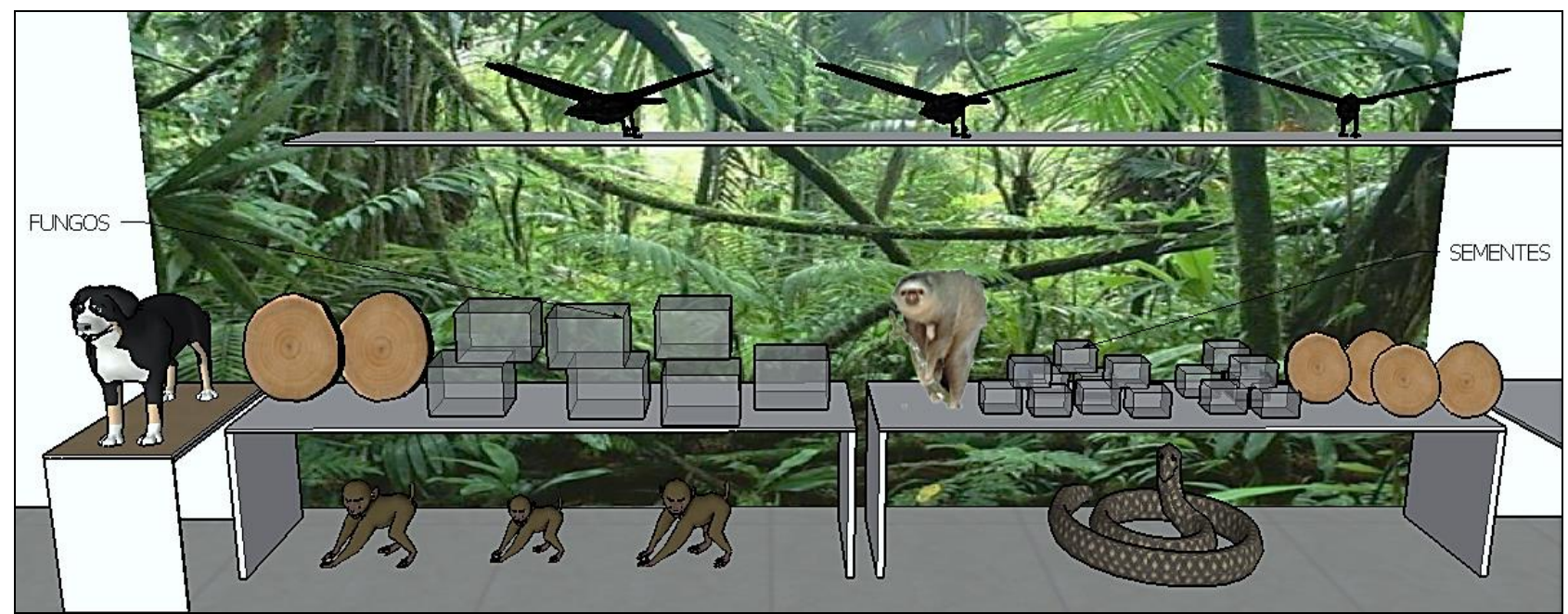

Figura 7. Análise de intervenção para o elemento madeira/árvore, com projeção para os 4 patamares de apresentação na seção de nestologia, aves, sementes e fungos.

Fonte: Autora (2016). Sem escala.

Tal representatividade em todos os patamares remete à similaridade do habitat da vida nas florestas. Com a ludicidade desta representação, a visibilidade é propositalmente alcançada em todos os ângulos de visão e atraente a diversos públicos.

Para tanto, sempre respeitando o já préexistente fluxo do acervo e também seguindo a ordem da teoria conceitual aplicada, apresentase o terceiro elemento: o fogo. Este acolherá a seção de rochas, minerais, artefatos e fósseis alguns destes provenientes deste elemento, que deverá ser indicado com um adesivo do magma ao chão, tal como indica a Figura 8.

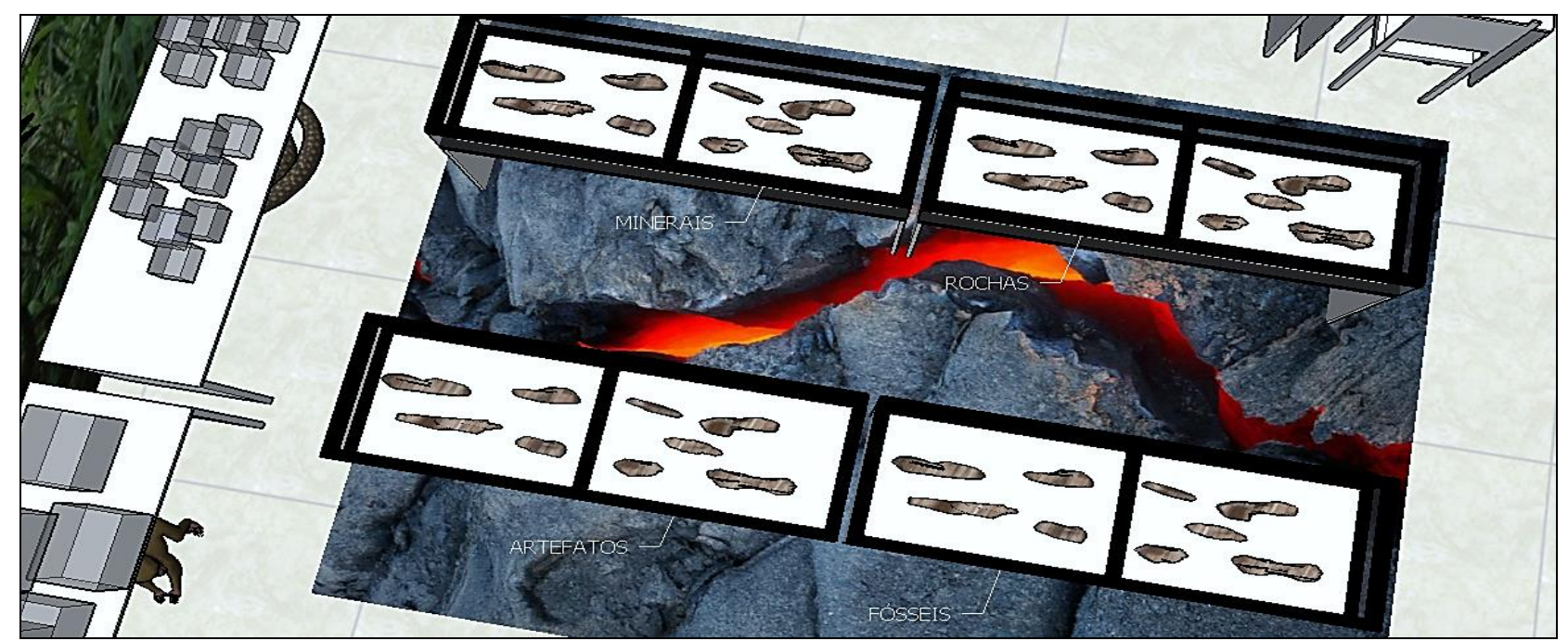

Figura 8. Projeção do elemento fogo na seção de minerais, rochas, fósseis e artefatos, alusivos à origem eruptiva vulcânica do magma.

Fonte: Autora (2016). Sem escala.

Exposto assim não seria prejudicial às peças, acompanharia a temática reorganizacional do acervo e seriam mantidas as amostras visíveis, pois permaneceriam no fundo branco, porém inseridas em sua origem, tal como as outras sessões.

Em continuidade, o quarto elemento da teoria Wu Ching, terra, poderia representar os organismos que vivem em contato com a mesma, ou seja, a seção da diversidade diminuta de seres, tais como os: insetos, aracnídeos, as serpentes e os embriões. Pensou-se neste elemento para ser aplicado nesta seção, pois, haveria de ser algo que englobasse a pequenez em todos seus patamares, tal como dispõe a Figura 9. 


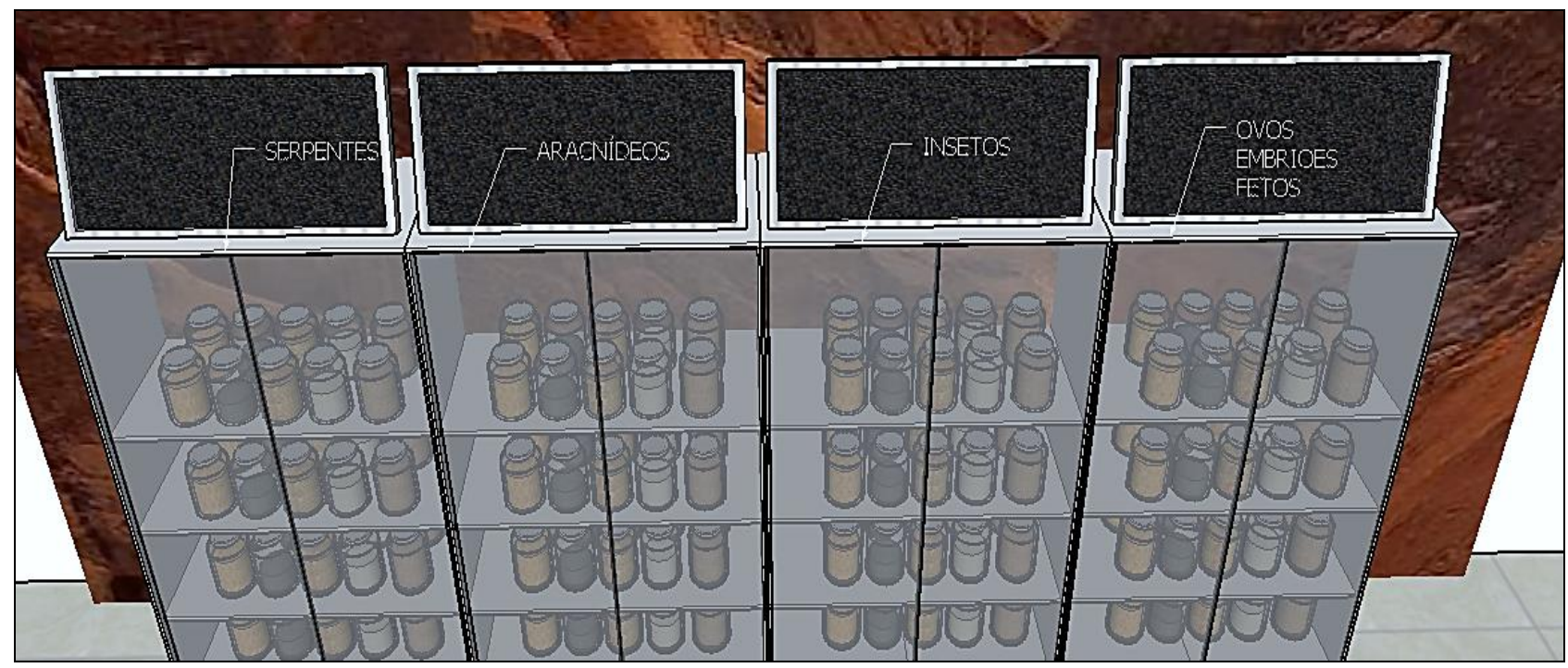

Figura 9. Aplicação do elemento terra, na seção de insetologia, serpentes e embriões.

Fonte: Autora (2016). Sem escala.

Por fim, têm-se o último elemento, representado na quinta e mais significativa repartição do $A E C I N$, o patrimônio do acervo que abriga a relação homem-animal. Ou seja, o segmento que contém os "Mamíferos", que é representada predominantemente por animais taxidermizados da fauna regional e domésticos. Esta seção receberá o elemento de maleabilidade mais rígida do diagrama para findar esta reavaliação arquitetônica: o elemento metal. Para tanto, este espaço será reorganizado com a transferência de parcela de répteis e peixes para a seção do elemento água, para serem empregados em seu elemento correspondente. Portanto, sugere-se que a seção de mamíferos seja representante única para o elemento metal, como se verá na Figura 10.

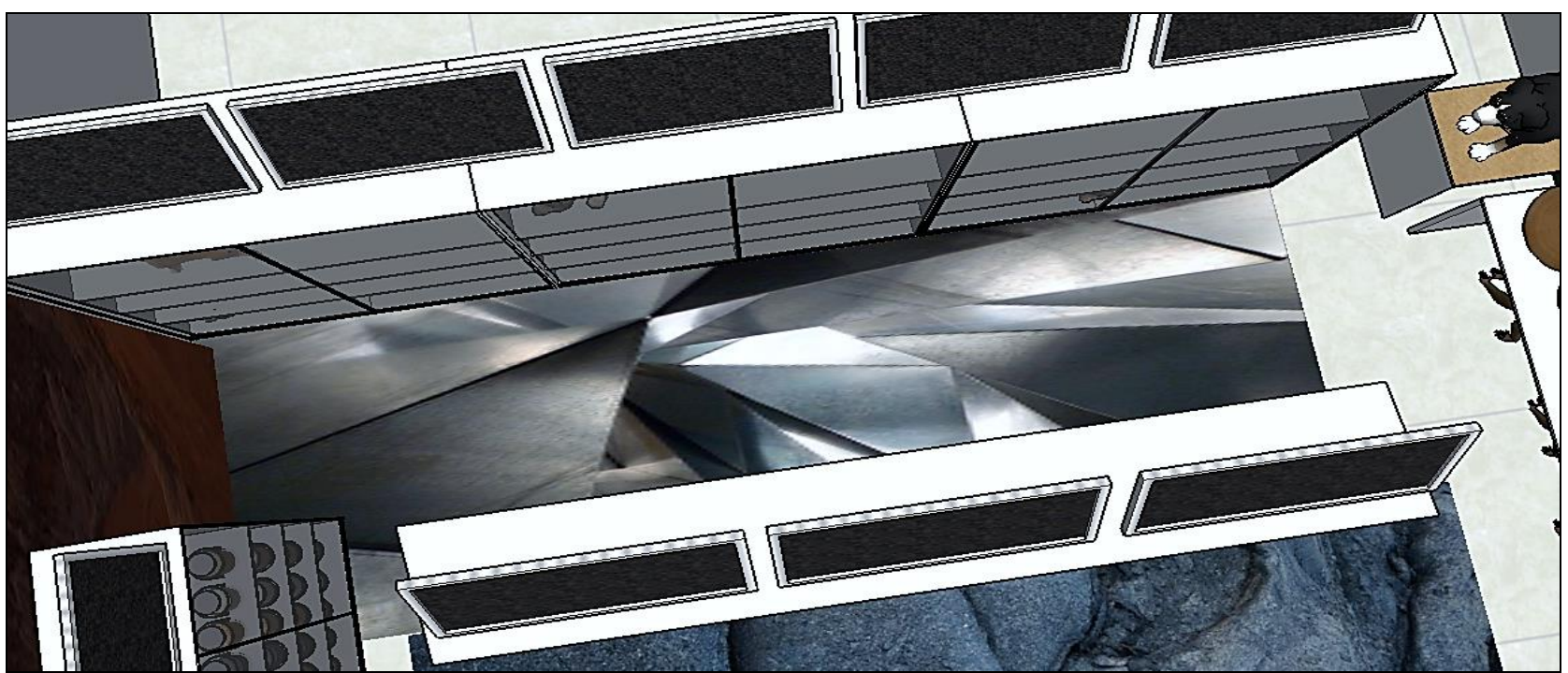

Figura 10. Reorganização da seção de mamíferos, que receberá o elemento de maleabilidade mais rígida do diagrama: o metal.

Fonte: Autora (2016). Sem escala.

Sendo aplicado o metal contorcido e aliado, demonstrando a relação que está transmitida nesta seção, com o adendo de que estes armários são os que possuem iluminação própria, faz-se alusão à teoria que a luz representa o fogo, único elemento que domestica o metal. Também se sugere uma placa de vidro no interior do armário expositor acrescentada conforme requisição com o propósito de ampliar o acervo. Em visão geral, temos que a cinza do magma apresentada no piso da seção de geociências será 
complementada pelo cinza do metal indicado na seção em questão.

Para complementar, também foi sugerido o estudo de um protótipo lúdico, permissivo ao toque, onde possa ser alcançado não só visualmente, mas experimentado e propagado, tornando-se um atrativo convidativo e, sobretudo, adequado às políticas inclusivas de acessibilidade destinadas a portadores de necessidades especiais.

Foi considerada útil a elaboração de um estudo de desapropriação espacial complementar, para que se concentre setor educativo (tanto acadêmico quanto para ações educativas e culturais) e sala para reuniões; proporcionando inclusive uma área particular ao setor administrativo e ao setor de serviços.

Finalmente, foi também elaborada a indicação de descentralização e o reposicionamento das tarefas na área técnica, com proposta de espaços reorganizados, mais adequados no que cerne o conforto do ambiente quanto à iluminação e ventilação, atingindo até a qualidade de circulação.

\section{DISCUSSÃO}

As intervenções propostas na presente pesquisa almejam fazer com que o AECIN tenha visibilidade, e que esta esteja em todos os níveis, desde o acolhimento aos visitantes e à sociedade em geral, externamente, quanto promover nitidez interna, fazendo com que, através das soluções arquitetônicas dispostas, esta permeabilidade seja alcançada pela comunidade acadêmica.

Obtendo o conceito arquitetônico, tanto à teoria aplicada quanto ao funcionamento do espaço do acervo para a melhoria do ambiente, o espaço se torna visivelmente organizado e atrativo à sociedade. Assim, o tema escolhido envolve a relação catalisadora entre coleções museológicas e arquitetura consumida na readequação do Acervo Educacional de Ciências Naturais (AECIN) da UNOESTE.

Perscrutam-se normativas museológicas e estratégias educacionais para nortear e embasar o desenvolvimento do mesmo. Atualmente, é dada importância à qualidade de vida e à excelência de uso espacial em lugares públicos que envolvam contato social, educacional e cultural. Para que isto aconteça, o espaço museológico analisado deve seguir regulamentação, buscar ações íntegras de preservação, conservação e restauração, maximizar as instalações e espaços museológicos atendendo o programa arquitetônico, pois estes estão diretamente relacionados à preservação das coleções, bem como ao bem-estar e à segurança do público e do corpo de funcionários da instituição.

As propostas de readequação apresentadas visam à melhoria da qualidade do ambiente e às indicações para exposições de peças como instrumento educacional em relação ao meio ambiente. A fundamentação da proposta de visitas virtuais para idealizar a intervenção no Acervo Educacional de Ciências Naturais da Universidade do Oeste Paulista justifica o desenvolvimento desta pesquisa. Além disto, promovem a discussão sobre propostas de readequação do AECIN sob a ótica da arquitetura, para a melhoria da qualidade de vida de seus frequentadores e o favorecimento das ações educativas decorrentes suas coleções museológicas.

Tomando por fim este posicionamento crítico-reflexivo, as propostas visam à maximização do bem estar dos frequentadores deste espaço museológico e o favorecimento das ações educativas decorrentes, tornando clara, a valiosa relação catalisadora entre coleções museológicas e arquitetura, que buscará ações íntegras, atendendo o programa arquitetônico e seguindo regulamentação normativa oficial pertinente.

\section{CONCLUSÃO}

Com a valiosa interdisciplinaridade e intervenção arquitetônica, espera-se que este espaço disponível ao AECIN da UNOESTE não só funcione melhor e tenha seu acervo melhor exposto qualitativamente e atrativamente, mas também possa promover um molde norteador para a prática da educação ambiental em coleções de Ciências Naturais, concluindo uma duplicidade de ambientes destinados a tal finalidade.

A visita à uma coleção de Ciências Naturais engrandece a alma e a formação de qualquer indivíduo. Somada à estruturação da prática de Educação Ambiental, proporciona o entendimento de questões discutidas em ambientes formais de ensino, promovendo reflexões por vezes inconcebíveis por meio de aulas expositivas ministradas no interior das escolas. 


\section{REFERÊNCIAS}

ASSOCIAÇÃO BRASILEIRA DE ECOMUSEUS E MUSEUS COMUNITÁRIOS - ABREMC. Portal da Associação Brasileira de Ecomuseus e Museus Comunitários. Disponível em: <http://www.abremc.com.br/>. Acesso em: 29 fev. 2016.

BRASIL. Ministério da Cultura. Instituto Brasileiro de Museus e Centros Culturais. Departamento de Processos Museais. Subsídios para a criação de Museus Municipais. Rio de Janeiro: IBRAM/ MinC, 2009. Disponível em: <http://www.museus.gov.br/wpcontent/uploads/2013/09/manual-subsidio-paracriacao-de-museu.pdf>. Acesso em: 25 fev. 2016.

COMITÊ BRASILEIRO DO CONSELHO INTERNACIONAL DE MUSEUS - ICOM. Portal do Comitê Brasileiro do Conselho Internacional de Museus. Disponível em: <http://icom.org.br>. Acesso em: 29 fev. 2016

CONSELHO FEDERAL DE MUSEOLOGIA - COFEM. Portal do Conselho Federal de Museologia. Disponível em: <http://cofem.org.br/>. Acesso em: 29 fev. 2016.

FAUBERT, G.; CREPON, P. A cronobiologia chinesa. São Paulo: Ibrasa, 1990.

KIEFER, F. Arquitetura de Museus. Porto Alegre: Revista ARQTEXTO, 2002.
MONTANER, J. M. Museus para o século XXI. 2. ed. Barcelona, Espanha: G. Gili, 2003.

SANTOS, F. H. dos. Metodologia aplicada em museus. São Paulo: Mackenzie, 2000.

SANTOS, M. C. T. M. Museus Universitários Brasileiros: Novas perspectivas. In: VI ENCONTRO DO FÓRUM PERMANENTE DE MUSEUS UNIVERSITÁRIOS. 6., SIMPÓSIO DE MUSEOLOGIA DA UFMG. "MUSEUS UNIVERSITÁRIOS - CIÊNCIA, CULTURA E PROMOÇÃO SOCIAL"2., 2006, Belo Horizonte. Anais... Belo Horizonte: UFMG, 2006.

SOUZA, G. P. O. Educação ambiental e o Acervo Educacional de Ciências Naturais da UNOESTE: atendimento à Rede Municipal de Tempo Integral de Presidente Prudente (SP) e sua inserção no Programa Mais Educação. 2015, 219 f. Dissertação (Mestrado). Universidade do Oeste Paulista - UNOESTE, Presidente Prudente, SP.

SUANO, M. O que é museu. São Paulo: Brasiliense, 1986.

UNIVERSIDADE DO OESTE PAULISTA. Acervo Educacional de Ciências Naturais. Regulamento Geral. Presidente Prudente: AECIN, 2013.

Recebido para publicação em 30/08/2016 Revisado em20/09/2016

Aceito em 21/09/2016 